Disponível em:

http://editora.unoesc.edu.br/index.php/race

RACE, Joaçaba, v. 16, n. 3, p. 1035-1058, set./dez. 2017

\title{
VANTAGEM COMPETITIVA DE UMA FRANQUIA NO SEGMENTO DE CHOCOLATES FINOS: UM ESTUDO NA PERSPECTIVA RESOURCE-BASED VIEW (RBV)
}

Competitive advantage of a franchise in the fines chocolate segment: a study in the ResourceBased View (RBV) perspective

Karla Dayane Bezerra Cruz

E-mail: karladay_cn@hotmail.com Mestre em Engenharia de Produção pela Universidade Federal do Rio Grande do

Norte; Especialista em Gestão Pública Municipal Universidade Federal do Rio Grande do Norte; Professora substituta na Universidade Federal do Rio Grande do Norte. Endereço para contato: Avenida Maria Augusta Pereira, 508, Parque Dourado, 59380-000, Currais Novos, Rio Grande do Norte, Brasil.

Laise Cristina Lima Pereira E-mail: laiselima@hotmail.com

Especialista em Gestão Estratégica de Negócios pela Universidade Federal do Rio Grande do Norte; Graduada em Administração pela Universidade Federal do Rio Grande do Norte; realiza a função de Apoio Administrativo Nível Superior no Serviço Brasileiro de Apoio às Micro e Pequenas Empresas (Sebrae) de Natal, Rio Grande do Norte.

Artigo recebido em 03 de maio de 2016. Aceito em 01 de agosto de 2017. 


\section{Resumo}

Neste artigo teve-se como objetivo explorar o estudo do modelo Resource Based View (RBV) aplicado em uma Franquia de chocolates finos - Cacau Show - localizada no Município de Currais Novos, RN. Buscou-se identificar os recursos que geram vantagem competitiva para a Franquia a partir de um questionário fechado aplicado à gestora e aos clientes, com base no modelo $R B V$ apresentado por Barney (2007), e que estão alinhados às escolhas dos clientes que compram na referida Franquia. A metodologia utilizada foi do tipo descritivo com enfoque quantitativo, cuja necessidade foi analisar as opiniões variáveis sobre os recursos: valor, humano, físico e organizacional, de forma que os resultados obtidos forneceram maior relação nos recursos humano e organizacional, que favoreceram a vantagem competitiva, principalmente no que se refere à qualidade no atendimento e dos produtos, além do acompanhamento das tendências do mercado. Os recursos de menor similaridade são: valor e físico, visto que os clientes não se expressaram exigentes nos aspectos localização e tecnologia da franquia, iluminação da loja e layout da empresa, tornando-se reais balizadores de sucesso, já que para o gestor essas condições são de extrema importância; por outro lado, os clientes são exigentes nos quesitos limpeza do ambiente, variedades de produtos e espaço físico, sendo estes, portanto, recursos que devem ser priorizados a fim de favorecer o destaque da Cacau Show no segmento de chocolates finos no mercado local.

Palavras-chave: Vantagem competitiva. Modelo RBV. Franquia. Estratégia empresarial. Mercado local.

\section{Abstract}

This article aimed to explore the study of Resource Based View (RBV) model, applied in a franchise of fine chocolates - Cacau Show - located in the city of Currais Novos, RN. The research sought to identify the resources that generate competitive advantage for the franchise from a questionnaire applied to management and customers, based on the RBV model presented by Barney (2007), and that are aligned with the choice of customers who buy in this Franchise. The methodology used was descriptive with quantitative approach, whose need was to analyze the variable opinions on resources: value, human, physical and organizational, so that the results provided greater relation in the human and organizational resources, that favored the competitive advantage, especially regarding the quality of service and products, and monitoring of market trends. The resources of smaller similarity are: value and physical, since customers were not demanding in the aspects location and franchise technology, store lighting and layout of the company, becoming a guide for real success, as for the manager of these conditions are of utmost importance; on the other hand, customers are demanding in environmental cleaning, product varieties and physical space, so these resources must be prioritized in order to favor the highlight of Cacau Show in the segment of fine chocolates in the local market.

Keywords: Competitive advantage. RBV model. Franchising. Business strategy. Local market. 


\section{INTRODUÇÃO}

O investimento no segmento de franquias vem sendo utilizado amplamente nos países desenvolvidos, já que promove o surgimento de pequenas empresas e, nos últimos tempos, o Brasil vem absorvendo esse mercado. Dessa forma, franchising é um forte impulsionador da abertura de novas empresas no País e tem, consequentemente, impulsionado a economia local.

Em um ambiente competitivo "o sistema de franchising vem ganhando visibilidade e atraindo interesse de diversos pesquisadores interessados em melhor compreender suas implicações econômicas e estratégicas (DAVIDOVITSCH; CALDAS; SILVA, 2009, p. 299).” Isso sucede em virtude do forte crescimento do setor de franquia no Brasil e no exterior, já que o setor possibilita o dinamismo na expansão de suas marcas, em razão do know-how que impulsiona consequentemente ganhos de escala, com custos e riscos baixos. A franquia é definida como um acordo contratual entre duas empresas independentes em que o franqueado paga ao franqueador pelo direito do uso da marca para vender o serviço ou o produto do franqueador.

O mercado competitivo desenvolve mecanismos de estratégia de diferenciação, de modo que aumenta o valor percebido dos produtos e/ou serviços para seus clientes, e, assim, é importante entender e relacionar a empresa ao seu ambiente. Dessa forma, a vantagem competitiva empresarial caracteriza-se pelo algo que os produtos e/ou serviços podem dar, além da forma capacitada e diferenciada que uma organização esteja em detrimento do concorrente (OLIVEIRA, 2010). Segundo Ribeiro, Rossetto e Verdinelli (2011), gera a vantagem competitiva a empresa que utiliza de forma coerente os recursos tangíveis e intangíveis, portanto é necessário investir e explorar os recursos para que melhore o desempenho da organização e, consequentemente, aumente a vantagem competitiva.

A organização com forte capacidade dinâmica é intensamente empreendedora, pois não somente consegue se adaptar ao ecossistema do negócio, mas também se molda por meio da inovação, e no caso das franquias, busca-se conhecer claramente aspectos como marca, habilidade de funcionários, padronizações dos processos e procedimentos eficientes, e isso garante o posicionamento competitivo.

O modelo Resource-Based View (RBV) se refere à visão baseada em recursos, e por meio dessa forma é possível identificar os níveis de relacionamento, canal de distribuição, conhecimento, competência, imagem no mercado, comprometimento, motivação, estrutura de layout, fidelidade, tecnologia de informação, cultura da corporação e propriedade intelectual. A Gestão Estratégica baseada na RBV carac- 
teriza o ambiente como dinâmico e potencialmente instável, justamente em razão da presença da concorrência entre as empresas e dos processos de inovação que estas se veem obrigadas a conduzir (CARVALHO; GRZEBIELUCKAS, 2006). A partir disso, pode-se mencionar o conceito de que não basta que a firma possua os recursos sem desenvolver a capacidade de gerir e coordenar o uso destes ao longo do tempo, em um ambiente interno e externo mutável.

Uma organização possui vantagem competitiva quando é capaz de gerar valor econômico maior que seus concorrentes. O presente estudo foi realizado na franquia da Cacau Show, que atua no segmento de chocolates finos, considerada a maior franquia de alimentos do Brasil e uma das maiores redes de chocolate do mundo. Seus produtos seguem o padrão internacional de qualidade alinhado a uma competitividade excelente.

Para tanto, pretende-se pesquisar a vantagem competitiva da franquia de chocolates finos Cacau Show, buscando informações dos gestores e clientes e a partir disso, conhecer o grau de similaridade entre os dados obtidos, de modo que as informações sirvam de suporte à organização para o planejamento estratégico de atuação no mercado local.

A problemática do estudo se baseia na identificação do que a empresa analisada faz bem e busca explorar a condição do mercado local a partir de informações identificadas pelo franqueado da Cacau Show e a correlação com a aspiração dos clientes da referida organização, tendo como objeto de pesquisa identificar se os recursos que a franquia utiliza, com base no modelo $R B V$, estão alinhados às escolhas dos clientes que compram produtos Cacau Show.

Dessa forma, o objetivo geral com a pesquisa é analisar a vantagem competitiva da Franquia de chocolates finos a partir do modelo $R B V$, e os objetivos específicos são identificar os recursos considerados como diferenciais estratégicos pelos gestores; investigar a percepção da franquia pelos clientes; identificar nos clientes o que eles admitem em termos de valor; pesquisar o que é difícil de ser imitado ou substituído; e propor melhorias de gestão a partir do modelo $R B V$.

O estudo se justifica de acordo com Barney (1991), que assegura que a $R B V$ analisa o recurso inserido no contexto empresarial tanto da empresa quanto do mercado em que está atuando; afirma, ainda, que as empresas e as condições são dinâmicas e devem ser observadas dentro desse contexto.

Este artigo justifica-se pela busca de indagar ou determinar se os recursos considerados como diferenciais estratégicos pelos gestores são objetos da mesma percepção dos clientes da Cacau Show. 


\section{REFERENCIAL TEÓRICO}

\subsection{A ESSÊNCIA DE FRANCHISING}

A Lei n. 8.955, de 15 de dezembro de 1994, define franchising como “[...] o sistema pelo qual o franqueador cede ao franqueado o direito de uso da marca ou patente, associado ao direito de distribuição exclusiva ou semi-exclusiva de produtos ou serviços e, o uso e implementação de tecnologia no negócio.”

A expansão da franchising corresponde a alguns termos que esclarecem o processo de inclusão do franqueado, que é o adquirente da franquia. A unidade de negócio operada pelo usuário é concedida a partir de método e processo de negócio pela franqueadora, a detentora dos direitos sobre a marca. Para isso, o franqueado paga a taxa de franquia pela concessão e know-how, alem da orientação e capacitação. Contudo, a franqueadora também recebe do franqueado uma taxa de royalties, que é paga com periodicidade definida e remunera a prestação de serviços prestados pela franqueadora ao franqueado. Ainda, é paga a taxa de marketing para uso em campanhas de divulgação nacional, regional ou local. Assim, todos esses direitos e obrigações são firmados em um contrato de franquia, documento legal que regera a relação entre franqueadora e franqueados, com aspectos legais e comerciais do negócio (RIBEIRO et al., 2011).

Franquia é o negócio gerido pelo franqueado o qual adquire a empresa do franqueador, que é o dono dos direitos da marca, a partir do pagamento de taxa da franquia, taxas de royalties e de marketing, ou seja, um valor de investimento inicial para abertura da firma e mensalmente taxa de manutenção da franquia, de modo que toda essa relação entre franqueador e franqueado ocorre a partir do contrato de franquia, que estabelece a legalidade da relação contratual. "Estratégias de crescimento para empresas que desejam alcançar novos mercados, o franchising dá a um negócio capacidade de penetrar rapidamente, e de dominar novos mercados, através do aumento do número de canais de distribuição ou pontos de venda.” (FOSTER, 1995).

O setor de franchising fortalece a marca, proporcionando ao negócio diferencial competitivo, já que proporciona autoestima, oportunidade de autogestão e um ativo duradouro (FOSTER, 1995).

O forte crescimento do segmento de franchising é favorecido pelas instituições financeiras que concedem empréstimos para aberturas de novos negócios, e já é garantido pelo crescimento de novos mercados geográficos e pela expansão das suas fontes de renda. Esse tipo de negócio desenha um padrão a ser seguido pelo 
franqueado, de modo que a padronização garante a qualidade da franquia, já que onde quer que o consumidor esteja estará adquirindo um serviço e/ou produto de qualidade (FOSTER, 1995).

O tipo de organização baseado em franquia é aquele em que o investidor é franqueador e passa a fornecer um serviço ao franqueado mediante remuneração. A genitora, portanto, passa a ter uma receita que provém dos resultados obtidos com a qualidade dos serviços de franquia prestados e não apenas do produto ou serviço original. Nesse caso, pensando exclusivamente no objeto de venda chamado "franquia”, o que pode diferenciar as propostas desses franqueadores pode ser, entre outros aspectos, a qualidade da transferência do conhecimento por parte destes ao franqueado.

\subsection{CARACTERIZAÇÃO DO OBJETO DA PESQUISA FRANQUIA CACAU SHOW}

A empresa Cacau Show foi fundada em 1988, ano em que se tornou reconhecida por vender luxuosamente chocolates diferenciados por preço acessível. Esse posicionamento fez com que a marca fosse crescendo e consolidando sua liderança no mercado nacional, e em 2004 a referida empresa deu início à sua operação de franquias, que foi fundamental para a expansão dos negócios (SUA FRANQUIA.COM, 2015).

A Cacau Show opera com dois tipos de franquias. O primeiro é o modelo clássico de lojas que podem ser localizadas em ruas com um bom fluxo de pessoas ou em shopping centers. A segunda opção são os quiosques da Cacau Show, modalidade que vem ganhando espaço no Brasil em razão do seu baixo investimento inicial. Ainda desmembrando, opera em três modelos, sendo adaptada a franquia de loja - loja convencional, loja light e loja express -, além da opção quiosque. O investimento na franquia convencional admite o valor de R \$ 135.000,00, com padrão de adequação em shoppings e pontos de rua com circulação de pessoas, e exige um espaço amplo; a loja light tem investimento de R \$110.500,00, com um padrão menor de franquia; a loja express pede investimento de R\$ 90.000,00 e é projetada para imóveis menores; por fim, os quiosques demandam investimento de R\$18.000,00 e área de quatro metros quadrados.

A Cacau Show oferece aos seus franqueados a força de apoio de uma equipe (apoio jurídico; apoio na montagem e inauguração da loja; auxílio na análise e escolha do ponto comercial; assistência inicial à operação da franquia; treinamento inicial do franqueado; manuais de implantação, administração e controle e marketing e vendas; treinamento constante Equipe Loja - E-learning; desenvolvimento do material promocional; indicação de fornecedores; marketing institucional estruturado; apoio 
no marketing local; assessoria de imprensa e consultoria permanente) (SUA FRANQUIA.COM, 2015).

A análise do trabalho será feita com base em uma franquia de loja tipo light, voltada a atender em um imóvel de dimensões menores, em local de fluxo constante de pessoas, em Currais Novos, RN, um município polo de outras cidades menores na região do Seridó com aproximadamente 45 mil habitantes.

\subsection{VANTAGEM COMPETITIVA}

A vantagem competitiva deve ser observada como uma estratégia que faça a empresa ser um diferencial no que ela faz. Não simplesmente vender um produto comum, mas um produto inovador, com uma nova fórmula, seja incrementada, seja transformadora. A visão baseada em recursos sugere que as vantagens competitivas podem ser encontradas em todos os setores da organização, da alta gerência aos funcionários. O importante para as empresas é criar valor econômico e deixar de criar paridade competitiva com concorrentes, para isso, é fundamental que os recursos estejam todos implementados para que, posteriormente, seja exposta a estratégia (VALLANDRO; TREZ, 2013).

A partir de modelo de estratégia a vantagem competitiva sustentável das empresas é proveniente de seus recursos, habilidades e competências, porém, isso acontece em ambiente incerto, competitivo e dinâmico. A fim de aprimorar os recursos que tendem a ser copiados ou imitados pela concorrência, é fundamental que a organização desenvolva ações que tornem os recursos duráveis e difíceis de serem identificados e compreendidos pelos concorrentes; para isso, são estudados a partir da teoria da vantagem competitiva. Portanto, é importante estudar a durabilidade, a transferibilidade, a transparência e a replicabilidade (CASTRO, 2009).

A priori, o estudo da durabilidade consiste na percepção de mudança a qual estimula o gestor a entender quando os recursos e capacidades depreciam ou se tornam obsoletos ao longo do tempo. A transparência remete à habilidade de sustentar a vantagem competitiva, de modo que depende da velocidade da mudança das empresas concorrentes. $\mathrm{O}$ estudo da transferibilidade possibilita transparecer que o concorrente consiga reunir recursos e capacidades necessárias para imitar e vencer um desafio competitivo, embora existam recursos como localização, informação e imobilidade das capacidades. A replicabilidade se estabelece quando os recursos são fáceis de serem imitados, e depende das organizações competidoras e do que elas fazem para imitar características de processos dos concorrentes (GRANT, 1991). 
O desafio que o gestor tem, atualmente, é identificar, desenvolver, proteger e desdobrar recursos e capacidades de forma a prover à firma uma vantagem competitiva sustentável e com retorno superior ao capital investido. Dessa forma, é importante o gestor organizacional visionar as capacidades dinâmicas de alcançar vantagem competitiva, de modo que se identifiquem as competências internas e as renovem sempre que não estejam fazendo efeito no crescimento empresarial, além de estabelecer o foco nos mercados e o posicionamento da marca de forma a atender à necessidade atual do ambiente no qual a corporação está inserida. Para isso, a implantação do modelo $R B V$ admite para a organização selecionar e/ou reconfigurar os estoques de recursos em razão das mudanças do ambiente competitivo e, dessa forma, assegura de maneira sustentável a integração dos ativos tangíveis e intangíveis como a verdadeira vantagem competitiva da organização (GUEDES, 2012).

Outro fator relevante quando se busca vantagem competitiva é identificar na empresa o crescimento de inteligência competitiva de modo que este não se limite apenas a uma avaliação interna da organização, mas que abranja uma avaliação externa que remeta a identificar o que acontece no mercado e principalmente o que o cliente está almejando (SILVA, 2007). Como forma de complementar essa busca contínua mencionada anteriormente, tem-se a necessidade de identificar os recursos considerados como diferenciais estratégicos pelos gestores da organização, além de investigar a percepção da firma pelos clientes por meio de um diagnóstico do que eles admitem em termos de valor, e também pesquisar o que é difícil de ser imitado ou substituído e propor melhorias de gestão a partir do modelo RBV (RIBEIRO, 2012).

\subsection{MODELO RBV}

O desenvolvimento da estratégia competitiva é demonstrado a partir de como a empresa conseguirá atingir suas metas e qual sua política para implementá-las. Além de que a organização deverá estar com a visão estratégica de dentro para fora, de modo a identificar claramente os recursos físicos, financeiros, intangíveis (marca, imagem e competências), organizacionais (cultura e sistemas administrativos) e humanos, e se caracteriza uma visão estratégica (GREVE; SALLES, 2006).

O principal objetivo do modelo RBV é desenvolver recurso a fim de que se torne vantagem competitiva para a organização; para isso, é necessário entender quais os recursos de valor, imitabilidade, raridade e organização. Assim, se um recurso de uma empresa é valioso, mas não é rara sua exploração, gera-se paridade com os concorrentes, de modo que esse recurso se iguala ao do concorrente; por outro 
lado, quando o recurso não é valioso e não é explorado pela organização, ele é visto como uma fraqueza que a corporação tem a obrigação de rever e reajustar. O que vai tornar a empresa competitiva no mercado é a vantagem competitiva por meio do dimensionamento do produto, de forma que este tenha valor para o cliente, seja raro no mercado e difícil de ser imitado e que os processos sejam estabelecidos da forma mais organizada e correta possível. O que vai definir o valor do produto é o quanto a empresa investe em qualidade para que se produza um produto com vantagem competitiva. O potencial de um recurso depende não apenas de sua existência em si, mas da identificação e da utilidade que se atribui a ele. E tal recurso apenas se reverterá em vantagem competitiva sustentável se for valioso, raro, difícil de imitar e difícil de substituir (BARNEY; HESTERLY, 2007).

Como forma de fortalecer a importância da aplicabilidade do modelo $R B V$, é reconhecida a importância da gestão dos recursos de capital físico (tecnologia, físicos e insumos), humano (os recursos de capital são denominados treinamentos, experiência e inteligência do pessoal que trabalha na empresa) e organizacional (recursos de sistema de planejamento, coordenação e controle). Reconhece-se, também, que para os recursos atenderem às suas funções, devem ter Valor, Raridade, Imitabilidade e Organização, sendo esses termos o significado do modelo aplicado VRIO. O modelo se firma a partir da ideia de valor quando a empresa explora oportunidade externa e neutraliza a ameaça do meio externo, nesse molde a organização está com seus recursos e capacidade valiosos. A raridade remete a poucos números de competidores, assim, o recurso ganha vantagem competitiva, já que poucos têm a disponibilidade dele. A imitabilidade se traduz na dificuldade do concorrente em identificar qual recurso se sobressai e gera vantagem competitiva da firma, portanto ele é difícil de ser imitado e gera estratégia competitiva sustentável.

A organização é determinada por sua estrutura formal de reporte, se ela tem o suporte de vantagem competitiva do valor, raridade e imitabilidade, facilitará a exploração ao máximo do potencial competitivo dos seus recursos; então, de fato, a organização é avaliada como intangível consistente (BARNEY; HERTERLY, 2007).

A partir do modelo $R B V$ a empresa ganha e sustenta vantagem competitiva de modo que o desenvolvimento dos recursos facilita a implementação das estratégias. Assim, cada setor da organização é responsável por construir a estratégia de alcançar os objetivos traçados para crescimento e desenvolvimento da corporação. Contudo, o modelo baseado em recursos provê uma visão de longo prazo em um ambiente incerto, competitivo e dinâmico. 
A abordagem baseada em recursos admite dois pressupostos: a heterogeneidade dos recursos entre setores, dentro de um mesmo segmento, e a mobilidade imperfeita desses recursos. Esses dois fatores visam atingir vantagem competitiva a qual deve ser elaborada com base na identificação dos recursos, como forma de torná-los raros e difíceis de serem imitados pelos concorrentes, e para isso a organização necessita implementar ações de inovação no ambiente empresarial consolidando sua vantagem competitiva. Para dimensionar essas ações serãá necessário que os recursos estejam pautados em um objetivo comum da empresa, o aumento da lucratividade.

O recurso que obtém característica de valioso, mesmo que seja comum a outros concorrentes, ajuda a empresa a criar estratégias que a coloquem em situação de paridade, e nessa condição, a chance de sobrevivência aumenta. Dentro da perspectiva de entender o modelo baseado em recursos, é salutar que a empresa fique responsável por determinar o que ela faz bem e busque explorar essa condição no mercado. Dessa forma, organizações que trabalham todos os recursos existentes (pessoas, tecnologia, financeiro, relacionamento, práticas e rotinas processuais e imagem no mercado) possivelmente se atentam na melhoria contínua, possibilitando que seja conservada a vantagem competitiva. A visão empresarial de dentro para fora torna a organização voltada para a competência, de modo que os recursos são aprimorados e estudados para tornar a empresa inovadora mercadologicamente, a fim de gerar impacto positivo no ambiente em que está inserida.

Assim, a questão-chave do estudo da $R B V$ é a maneira pela qual as firmas conseguem alcançar e manter a vantagem competitiva por meio da exploração dos recursos. Portanto, é imprescindível que seja avaliada a questão do valor, já que favorece a exploração da oportunidade, neutralizando a ameaça do concorrente.

Segundo Barney (2007) a forma como o valor, a raridade e a imitabilidade são administrados por uma firma implica tanto questões formais quanto informais, tangíveis e intangíveis. Dessa forma, é admissível, também, que o estudo seja pautado no valor de mercado que cada recurso pode trazer à empresa, portanto é importante que a organização tenha claro quais recursos lhe trarão vantagem competitiva futura e os mantenha sempre aperfeiçoados, de modo que eles determinem o caminho para atingir o sucesso, ou sejam um guia para a estratégia da organização.

O fator preponderante para o sucesso estratégico da organização é identificar os principais recursos para se obter a competitividade do negócio, contudo é efetivo o resultado a partir da criação de uma rede de recursos que possibilite a posição de difícil imitação no mercado, pois a sinergia na aplicabilidade dos recursos favorece o diferencial competitivo da empresa. 
Ambrosini, Bowman e Burton-Taylor (2007) desenvolveram o desafio de articular a $R B V$ à perspectiva prática e descobriram, por meio de uma análise detalhada das microatividades realizadas por uma equipe, como as atividades coordenadas foram cruciais para os resultados estratégicos (no caso específico, a satisfação do cliente). Jarzabkowski, Balogun e Seidl (2007) reconhecem que esse trabalho é um avanço, de modo que ajuda a compreender as estratégias que podem ser destacadas pela utilização da perspectiva prática.

Embora exista a possibilidade de desenvolver a pesquisa com o foco voltado para outros níveis da organização, especificamente o trabalho de Ambrosini, Bowman e Burton-Taylor (2007, p. 61) concentra sua "abordagem no micro nível” como forma de "compreender resultados estratégicos." Nesse sentido, os autores atenderam ao desafio lançado por Johnson, Melin e Whittington (2003, p. 3), ao buscarem nas “[...] atividades do dia-a-dia da organização [...]” (práxis) uma explicação para “[...] os resultados estratégicos.”

Entretanto, é importante salientar que nem todas as atividades realizadas são estratégicas, o que vai ao encontro do argumento defendido por Barney (1991) ao considerar como estratégicos os recursos que têm o potencial de gerar vantagem competitiva, daí a importância da identificação da necessidade do cliente, bem como dos recursos que poderão ser utilizados da melhor forma para atender a essa necessidade.

A pesquisa da Franquia de chocolates finos a partir da perspectiva do modelo $R B V$ tem por finalidade comparar as visões interna e dos clientes, de forma a compreender o comportamento da estrutura gerencial dentro do processo decisório como um potencial recurso de fator que gere vantagem competitiva sustentável se for valioso, raro, difícil de imitar e difícil de substituir.

\section{METODOLOGIA DA PESQUISA}

Em decorrência da justificativa do artigo, o método de pesquisa é descritivo, tendo como meta obter informações sobre uma população (cliente), identificando o funcionamento e os principais resultados apresentados. Se o propósito do estudo implica medir relações entre variáveis (associação ou causa-efeito), o delineamento da pesquisa garante uma boa interpretação de resultados com a técnica de coleta, enfoque da pesquisa quantitativa (ROESCH, 2007) e descritiva (MARCONI; LAKATOS, 2010), que consiste em investigações da pesquisa, cujo objetivo é analisar opiniões variáveis à descoberta de dados sobre características de fatos, com a finalidade de fornecer dados para a verificação de programas, por meio de questionário com o gestor 
e os clientes da franquia de chocolates finos Cacau Show no Município de Currais Novos, RN.

Enquanto isso, são avaliados na pesquisa quais recursos financeiros, físicos, humanos e organizacionais são considerados estratégicos para o posicionamento mercadológico da franquia, segundo as visões do gestor e o contraponto com o cliente, com o objetivo de obter algumas informações acerca da vantagem competitiva da Cacau Show.

A pesquisa foi realizada com 3,47\% dos clientes da empresa, ou seja, 52 pesquisados para um total de 1.500 clientes. Contudo, a margem de erro foi de $3 \%$, com nível de confiança de 34\% (NOGUEIRA, [2003?]). A amostra não probabilística por conveniência ocorreu por meio de escolha da amostra pelo pesquisador, dessa forma, abordaram-se os clientes da Franquia de chocolates finos no Município de Currais Novos, RN, para obtenção de informações para a pesquisa (SAMARA; BARROS, 2007).

A técnica de coleta usada são os questionários que, segundo Roesch (2007, p. 142), “é o instrumento utilizado em pesquisa quantitativa, principalmente em pesquisas de escala, como as que se propõem levantar a opinião política da população ou a preferência do consumidor.” Dessa forma, a elaboração é complexa e exige seleção das questões pela importância de obter informações válidas, além de virem detalhadas instruções objetivas e claras para o entrevistado. Quanto ao tipo de questões, estas podem ser fechadas ou abertas, ou alguma combinação entre elas (ROESCH, 2007). O alvo de investigação e o seu instrumento de relação da pesquisa foi um questionário estruturado e com alternativas (questionário fechado), aplicado aos clientes e ao gestor, com o objetivo de questionar ou estabelecer parâmetros que determinem se os recursos considerados como diferenciais estratégicos pelo gestor são os objetos da mesma percepção pelos clientes.

Realizou-se a aplicação do instrumento estruturado constituído de quatro aspectos avaliados (Recursos: valor, humanos, físico e organizacional) distribuídos em 37 questões fechadas, a partir da escala tipo Likert de cinco pontos. Buscou-se identificar o nível de importância (sem importância (1); pouco importante (2); importante (3); muito importante (4); e extremamente importante (5)). A obtenção do resultado da pesquisa ocorreu por meio do cálculo da média ponderada no qual se multiplicou o peso de cada nível de importância pela frequência das respostas e dividiu-se o valor pelo total de pesquisados (SAMARA; BARROS, 2007).

O conhecimento decorrente da avaliação de desempenho organizacional é um recurso que está alinhado com a estratégia competitiva da franquia, de acordo com a perspectiva do modelo $R B V$; a coleta de informações visa a uma equiparação do mo- 
delo, a fim de aliar o desempenho da empresa a partir de recursos estratégicos, com a avaliação de importância dos clientes.

\section{RESULTADOS E DISCUSSÕES}

O estudo que confirma a teoria a partir da análise da vantagem competitiva por meio do modelo $R B V$ estará discutindo e identificando os principais recursos considerados importantes na visão dos clientes em similaridade com o gestor da Franquia da Cacau Show localizada no Município de Currais Novos, RN.

\subsection{ANÁLISE DO RECURSO VALOR}

O Recurso Valor foi pesquisado com o intuito de demonstrar diante dos objetivos os recursos considerados diferenciais estratégicos, de modo que foram pesquisados os níveis de importância: preço, condições de pagamento nas compras, embalagens em que são armazenados os chocolates, formatos dos chocolates, sabores dos chocolates, folders das campanhas da franquia, padronização de fardamento e aparência dos colaboradores, e divulgação da franquia em mídias locais (rádio, TV local a cabo e blogs).

Quadro 1 - Recurso Valor atribuído pelo gestor da Franquia Cacau Show

\begin{tabular}{|l|l|}
\hline \multicolumn{1}{|c|}{ Recurso Valor } & \multicolumn{1}{|c|}{ Nível de importância } \\
\hline Preço & Importante \\
\hline Condições de pagamento nas compras & Importante \\
\hline Embalagens em que são armazenados os chocolates & Muito importante \\
\hline Formatos dos chocolates & Muito importante \\
\hline Sabores dos chocolates & Muito importante \\
\hline Folders das campanhas da Franquia & Extremamente importante \\
\hline Padronização de fardamento dos funcionários & Extremamente importante \\
\hline Aparência dos funcionários & Extremamente importante \\
\hline Divulgação da Franquia em mídias locais (rádio, TV a cabo e blogs) & Muito importante \\
\hline
\end{tabular}

Fonte: os autores. 
No Quadro 1, ao que remete à identificação dos recursos estratégicos na visão do gestor, observa-se que estão atrelados à padronização de fardamento dos funcionários, aos folders das campanhas e à aparência dos colaboradores, sendo, portanto, diferente da visão apontada pelos clientes da franquia no Município de Currais Novos.

Tabela 1 - Recurso Valor atribuído pelos clientes

\begin{tabular}{lc}
\hline \multicolumn{1}{c}{ Recurso Valor } & Média \\
\hline Preço (R\$) & 3,60 \\
Condições de pagamento nas compras & 3,65 \\
Embalagens em que são armazenados os chocolates & 4,00 \\
Formatos dos chocolates & 3,25 \\
Sabores dos chocolates & 4,46 \\
Folders das campanhas da Franquia & 3,21 \\
Padronização de fardamento dos funcionários & 3,60 \\
Aparência dos funcionários & 3,73 \\
Divulgação da Franquia em mídias locais (rádio, TV a cabo e blogs) & 3,54 \\
\hline Fonte: os autores. &
\end{tabular}

De acordo com a Tabela 1, identificou-se que as embalagens em que são armazenados os chocolates é o atributo de maior importância, bem como os sabores dos chocolates, revelando a necessidade de atender ao nível máximo de qualidade na produção, aliando inovação e diversidade de sabores com diferenciais em textura e cor. Desse modo, é relevante para a Franquia sugerir ao franqueador o investimento no desenvolvimento de novas embalagens, aplicando a inovação nos produtos. Outro recurso que obteve alto nível de importância é a aparência da equipe de trabalho, visto que para o segmento de alimentos é primordial a boa aparência dos colaboradores, bem como limpeza, vestimenta e bem-estar. Churchill e Peter (2000) afirmam que a imagem física do produto também deve ser considerada, pois uma embalagem ou rótulo atraente pode influenciar a confiança de compra do cliente.

Os recursos de valor garantem vantagem competitiva da Franquia perante os concorrentes, portanto a visão de valor dos clientes pesquisados deverá provocar o gestor a realizar a avaliação constante de melhorias de acordo com a exposição dos clientes no que foi pesquisado, como o nível de importância no que se refere a recurso de valor. 


\subsection{ANÁLISE DO RECURSO HUMANO}

A análise do Recurso Humano contribuirá para identificar, na pesquisa, os recursos que podem ser imitados ou substituídos para a busca de estratégia com foco na vantagem competitiva; dessa forma, foram pesquisados os recursos: treinamento do funcionário, conhecimento do produto por parte do vendedor (confiabilidade), satisfação do vendedor com o trabalho, se a quantidade de funcionários supre a demanda da empresa, liberdade do funcionário em resolver eventualidades, qualidade no atendimento, relacionamento com o proprietário (confiança/satisfação) e segurança do contratado.

Quadro 2 - Recurso Humano atribuído pelo gestor

\begin{tabular}{|l|l|}
\hline \multicolumn{1}{|c|}{ Recurso Humano } & \multicolumn{1}{|c|}{ Nível de importância } \\
\hline Treinamento do funcionário & Extremamente importante \\
\hline Conhecimento do produto por parte do vendedor (confiabilidade) & Muito importante \\
\hline Satisfação do vendedor com o trabalho & Muito importante \\
\hline Quantidade de funcionários supre a demanda da empresa & Importante \\
\hline Liberdade do funcionário em resolver eventualidades & Importante \\
\hline Qualidade no atendimento & Extremamente importante \\
\hline Relacionamento com o proprietário (confiança/satisfação) & Muito importante \\
\hline Segurança contratado & Muito importante \\
\hline
\end{tabular}

Fonte: os autores.

No Quadro 2, quanto às informações da pesquisa realizada pelo gestor, identifica-se que a qualidade no atendimento é considerada estratégica para a Franquia, de modo que se determina que os recursos de qualidade no atendimento e treinamento do funcionário são considerados diferenciais estratégicos pelo gestor e são objetos da mesma percepção dos clientes. 
Tabela 2 - Recurso Humano atribuído pelos clientes

\begin{tabular}{lc}
\hline \multicolumn{1}{c}{ Recurso Humano } & Média \\
\hline Treinamento do funcionário & 4,31 \\
Conhecimento do produto por parte do vendedor & 4,25 \\
Satisfação do vendedor com o trabalho & 4,21 \\
Quantidade de funcionários supre a demanda da empresa & 3,96 \\
Liberdade do funcionário em resolver eventualidades & 3,83 \\
Qualidade no atendimento & 4,60 \\
Relacionamento com o proprietário (confiança/satisfação) & 4,04 \\
Segurança do contratado & 3,52 \\
\hline Fonte: os autores. &
\end{tabular}

Na Tabela 2, a análise do Recurso Humano apresenta nível de maior importância na visão do cliente da Franquia Cacau Show para a qualidade no atendimento, que exige padronização em se tratando de franquia, para a abordagem do cliente. Portanto, a qualidade no atendimento é um ingrediente crítico de sucesso, pois o colaborador é responsável pelo contato intenso com os clientes e pode influenciar na concepção destes. O funcionário de contato é o próprio serviço, e tudo que ele fizer influenciará no juízo do cliente a respeito da organização (KHENAYFIS, 2010).

Portanto, é salutar a importância do treinamento de colaboradores, não apenas para atender bem o cliente, mas também para saber responder a questões específicas sobre os produtos. Para tanto, foi identificado na pesquisa o maior grau de similaridade entre a visão do gestor e dos clientes no que se refere ao recurso humano; qualidade no atendimento e treinamento do funcionário foram de extrema importância para o bom funcionamento da Franquia.

\subsection{ANÁLISE DO RECURSO FÍSICO}

Os recursos físicos são importantes para identificar na pesquisa o contexto empresarial tanto da empresa quanto do mercado em que está atuando. Foram avaliados: proximidade da Franquia com o ponto de abastecimento dos chocolates, localização da Franquia, variedade de produtos, tecnologia da Franquia, aparência das gôndolas (local de exposição dos produtos), iluminação da loja, layout da empresa, aroma convidativo à venda, limpeza do ambiente, segurança eletrônica e espaço físico da loja. 
Quadro 3 - Recurso Físico atribuído pelo gestor

\begin{tabular}{|l|l|}
\hline \multicolumn{1}{|c|}{ Recurso Físico } & \multicolumn{1}{|c|}{ Nível de importância } \\
\hline Proximidade da Franquia com o ponto de abastecimento dos chocolates & Muito importante \\
\hline Localização da Franquia & Extremamente importante \\
\hline Variedade de produtos & Muito importante \\
\hline Tecnologia da Franquia & Extremamente importante \\
\hline Aparência das gôndolas (local de exposição dos produtos) & Extremamente importante \\
\hline Iluminação da loja & Extremamente importante \\
\hline Layout da franquia (decoração, localização dos móveis e prateleiras) & Extremamente importante \\
\hline Aroma convidativo à venda & Muito importante \\
\hline Limpeza do ambiente & Muito importante \\
\hline Segurança eletrônica da loja & Muito importante \\
\hline Espaço físico da loja & Importante \\
\hline
\end{tabular}

Fonte: os autores.

No Quadro 3 o gestor retrata a necessidade de atender ao padrão de franquia, ou seja, demonstra o que a Franquia faz bem, e, portanto, os recursos físicos são favoráveis ao seu bom funcionamento, com níveis de importância superiores para localização, tecnologia, aparência das gôndolas, iluminação e layout.

Tabela 3 - Recurso Físico atribuído pelos clientes

\begin{tabular}{lr}
\hline \multicolumn{1}{c}{ Recurso Físico } & Média \\
\hline Proximidade da Franquia com o ponto de abastecimento dos chocolates & 3,46 \\
Localização da Franquia & 4,06 \\
Variedade de produtos & 4,36 \\
Tecnologia da Franquia & 3,60 \\
Aparência das gôndolas (local de exposição dos produtos) & 4,06 \\
Iluminação da loja & 3,73 \\
Layout da franquia (decoração, localização dos móveis e prateleiras) & 3,77 \\
Aroma convidativo & 3,88 \\
Limpeza do ambiente & 4,48 \\
Segurança eletrônica da loja & 3,73 \\
Espaço físico da loja & 4,08 \\
\hline
\end{tabular}

Fonte: os autores. 
Observa-se na Tabela 3 que os clientes consideram extremamente importantes a limpeza do ambiente, a variedade de produtos e o espaço físico. Morgan e Powell (2010, p. 15) escrevem que "mais do que nunca, as lojas físicas precisam fazer com que os consumidores entrem e comprem e o visual merchandising é fundamental para atrair e prender a atenção dos clientes.”

Assim, analisando os recursos físicos interessantes no ponto de vista dos clientes, conclui-se que limpeza do ambiente, variedade de produtos, espaço físico e aparência das gôndolas são itens que favorecem o visual merchandising e estimulam a venda na franquia de chocolates finos.

\subsection{ANÁLISE DO RECURSO ORGANIZACIONAL}

A análise do Recurso Organizacional permitiu à pesquisa identificar se existe correlação com a aspiração dos clientes da Franquia, de modo que foi observado o nível de importância dos seguintes itens: planejamento estratégico da empresa para atender às necessidades dos clientes, acompanhamento do mercado, confiabilidade da marca, propaganda, reposição de estoque, atendimento, qualidade dos produtos, atrativo da Franquia e constância no lançamento de produtos.

Quadro 4 - Recurso Organizacional atribuído pelo gestor

\begin{tabular}{|l|l|}
\hline \multicolumn{1}{|c|}{ Recurso Organizacional } & Nível de importância \\
\hline $\begin{array}{l}\text { Planejamento estratégico da Franquia para atender às necessidades dos } \\
\text { clientes }\end{array}$ & Importante \\
\hline Acompanhamento do mercado (inovação) & Extremamente importante \\
\hline Confiabilidade da marca & Muito importante \\
\hline Propaganda & Importante \\
\hline Reposição de estoque & Muito importante \\
\hline Atendimento rápido & Importante \\
\hline Qualidade dos produtos & Extremamente importante \\
\hline Franquia é um atrativo & Importante \\
\hline Constante lançamento de produtos & Muito importante \\
\hline
\end{tabular}

Fonte: os autores.

O posicionamento do gestor da Franquia transmite alinhamento com as escolhas dos clientes, ou seja, os recursos organizacionais que são considerados estratégicos para o favorável andamento da Franquia Cacau Show no Município de Currais 
Novos, RN. Em razão da vivência do ambiente competitivo, caracterizado por intensa concorrência em nível global, pela emergência de mercados divididos e com consumidores exigentes e sofisticados, e por mudanças tecnológicas rápidas, diferenciadas e renovadoras, as empresas estão sujeitas a pressões constantes para a melhoria da qualidade dos produtos (TOLEDO, 1994). Portanto, o recurso qualidade na visão do gestor traduz uma importância extrema da Franquia para seu consumidor de chocolates.

Tabela 4 - Recurso Organizacional atribuído pelos clientes

\begin{tabular}{lr}
\hline \multicolumn{1}{c}{ Recurso Organizacional } & Média \\
\hline Planejamento estratégico da Franquia para atender às necessidades dos clientes & 3,92 \\
Acompanhamento do mercado (inovação) & 4,15 \\
Confiabilidade da marca & 4,33 \\
Propaganda & 3,56 \\
Reposição de estoque & 4,06 \\
Atendimento rápido & 4,11 \\
Qualidade dos produtos & 4,52 \\
Franquia é um atrativo & 3,77 \\
Constante lançamento de produtos & 3,88 \\
\hline Fonte: os autores.
\end{tabular}

Na Tabela 4, a análise do Recurso Organizacional traduz o nível de importância do recurso qualidade dos produtos. Por isso da exigência de processos que garantam um produto padronizado para todo o País, além da confiabilidade da marca, isso, é claro, a partir de padrões conformizados e exigidos pela Franquia Cacau Show. Outro recurso importante é o acompanhamento do mercado, atrelado à inovação do segmento de chocolates, pois não se trata de apenas vender bombons, é necessário atender ao desejo do consumidor com inovação e diferencial competitivo.

É percebido grau de similaridade entre os recursos organizacionais, demonstrando alinhamento entre o andamento da Franquia e a necessidade dos clientes. Os recursos que demonstraram maior paridade foram a qualidade dos produtos e o acompanhamento do mercado (inovação).

\section{CONSIDERAÇÕES FINAIS}

Nesta pesquisa buscou-se identificar o grau de similaridade entre os recursos valor, humano, físico e organizacional, observando-se de modo estratégico a visão do 
gestor e identificando a percepção dos clientes da Franquia Cacau Show no Município de Currais Novos, RN. Assim, um dos objetivos da pesquisa foi avaliar o grau de posicionamento do gestor e do cliente, a fim de fornecer suporte à organização para o planejamento estratégico de atuação no mercado local.

Tendo considerado o modelo Resource-Based View (RBV), utilizou-se o método quantitativo com questões fechadas a partir da escala Likert observando os níveis de importância por meio de um peso estabelecido, a fim de identificar os recursos de valor, humano, físico e organizacional da franquia e seus níveis de importância. Os resultados obtidos identificaram uma conformidade no que se refere à vantagem competitiva da Franquia Cacau Show com a percepção do cliente; dessa forma houve uma similaridade principalmente na avaliação dos recursos humano e organizacional.

Portanto, o resultado obtido a partir da escala tipo Likert, que mensura o nível de importância durante a pesquisa, resultou na parecença da qualidade do atendimento e no treinamento do funcionário para uma avaliação de recurso humano, aparecendo, também, na qualidade dos produtos e no acompanhamento do mercado para a análise organizacional. Assim, é favorável que esses aspectos sejam analisados, já que estão alinhados no que se refere à vantagem competitiva sustentável, em que se classificam como valorosos, raros e difíceis de ser imitados.

Os resultados encontrados possibilitam a compreensão da análise dos recursos de valor e físico que a Franquia explora com base no padrão exigido e nas normas que os recursos localização e tecnologia da Franquia, aparência das gôndolas, iluminação da loja e layout da empresa são reais balizadores de sucesso, visto a condição do mercado local do Município, o que favorece o destaque da Cacau Show em Currais Novos, RN, despertando no público local padrões não vislumbrados. Na correlação com a aspiração dos clientes no que se refere aos recursos de valor e físico, são atribuídos níveis de extrema importância aos sabores dos chocolates, embalagens em que são armazenados os chocolates, limpeza do ambiente, variedade de produtos e espaço físico da Franquia. Dessa forma, também é relevante para a vantagem competitiva da Cacau Show no mercado de Currais Novos considerar esses níveis de importância atrelados aos recursos citados pelos clientes, de modo que a estratégia da Franquia vislumbre a melhoria desses recursos com o objetivo de gerar valor econômico maior e suporte para uma atuação no mercado local.

Assim, acredita-se que a presente pesquisa tenha trazido entendimento da aplicação do modelo $R B V$ na análise dos recursos da Franquia Cacau Show, concatenando em uma correlação de aspirações entre o gestor e os clientes da Franquia, com o intuito de favorecer a vantagem competitiva aliada a fatores que realmente causam 
resultados às organizações que trabalham estrategicamente. Assim, os objetivos propostos foram atingidos a partir da análise da similaridade dos posicionamentos do gestor e dos clientes, favorecendo o suporte estratégico de fortalecimento da Franquia de chocolates finos no mercado local.

\section{REFERÊNCIAS}

AMBROSINI, V.; BOWMAN, C.; BURTON-TAYLOR, S. Inter-team coordination activities as a source of customer satisfaction. Human relations, v. 60, n. 1, p. 5998, 2007.

BARNEY, J. B.; HESTERLY, W. S. Administração estratégica e vantagem competitiva. São Paulo: Pearson Prentice Hall, 2007.

BARNEY, J. The Resource-Based Model of the Firm: Origins, Implications, and Prospects. Journal of Management, v. 17, 1991.

BRASIL. Lei n. 8.955, de 15 de dezembro de 1994. Dispõe sobre o contrato de franquia empresarial (franchising) e dá outras providências. Diário Oficial da União, Brasília DF, 16 dez. 1994.

CARVALHO, L. F.; GRZEBIELUCKAS, C. Vantagem Competitiva na visão baseada em recursos. In: SEMANA DO CONTADOR, 18., 2006, Maringá. Anais... Maringá: UEM-DCC, 2006.

CASTRO, V. A. Gestão do conhecimento - CG - Como recurso estratégico e fonte de vantagem competitiva sustentável - VCS - na perspectiva Resource-based view - RBV-. 2009. 209 p. Dissertação (Mestrado em Administração)-Universidade Federal de Uberlândia, Uberlândia, 2009.

CHURCHILL, G. A.; PETER, J. P. Marketing: criando valor para o cliente. São Paulo: Saraiva, 2000.

DAVIDOVITSCH, L.; CALDAS, L. F.; SILVA, J. F. Estruturação das redes de fastfood: um estudo empírico sobre os antecedentes do franchising e suas implicações sobre o desempenho das firmas. Revista de Administração, 2009, v. 44, n. 4, p. 299-312, 2009.

FOSTER, D. L. O livro completo do Franchising. Rio de Janeiro: Infobook, 1995. 
GRANT, R. M. The resource-based theory of competitive advantage: implications for strategy formulation. California Management Review, spring 1991.

GREVE, J. T.; SALLES, J. A. A. Estratégia baseada em recursos, estratégia baseada no mercado análise swot: conceitos únicos ou separados. In: SIMPÓSIO DE ENGENHARIA DE PRODUÇÃO, 13., 2006, São Paulo. São Paulo, 2006.

GUEDES, A, A. et al. Capacidades dinâmicas e vantagens competitivas: Um estudo em uma construtora com foco no mercado de baixa rendas. São Paulo: Simpoi, 2012.

JARZABKOWSKI, P.; BALOGUN, J.; SEIDL, D. Strategizing: The challenges of a practice perspective. Human Relations, v. 60, n. 5, 2007.

JOHNSON, G.; MELIN, L.; WHITTINGTON, R. Micro Strategy and Strategizing: Towards an Activity-Based View. Journal of Management Studies, v. 40, i. 1, p. 3-22, 2003.

KHENAYFIS, S. A. A influência da qualidade do atendimento na decisão de compra. 2010. 93 p. Dissertação (Mestrado em Gestão Empresarial)-Fundação Getúlio Vargas, Rio de Janeiro, 2010.

MARCONI, M. de A.; LAKATOS, E. M. Fundamentos de Metodologia Científca. 7. ed. São Paulo: Atlas, 2010.

MORGAN, T.; POWELL, K. Visual merchandising: escaparates e interiores comerciales. Barcelona: GG, 2010.

NOGUEIRA, L. S. Inferência estatística: planilhas eletrônicas para o cálculo de tamanho de amostra, margens de erro e intervalos de confiança com a técnica de amostragem aleatória simples envolvendo problemas de estimação de médias e proporções. Tangará da Serra: Unemat, [2003?].

OLIVEIRA, D. de P. R. de. Estratégia Empresarial \& Vantagem Competitiva: Como Estabelecer, Implementar e Avaliar. São Paulo: Atlas, 2010.

RIBEIRO, A. et al. Gestão Estratégica do Franchising: como construir redes de Franquias de sucesso. São Paulo: DVS, 2011. 
RIBEIRO, Ronaldo. Análise da formação de recurso estratégico segundo a RBV: estudo em uma organização educacional. Revista de Gestão e tecnologia NAVUS. NAVUS, Florianópolis, v. 2, n. 1, jan./jun. 2012.

RIBEIRO, R.; ROSSETTO, C. R.; VERDINELLI, M. A. Comportamento estratégico da empresa e a visão baseada em recursos: um estudo no setor varejista de material de construção. Gestão e Produção, 2011.

ROESCH, S. M. A. Projetos de estágio e de pesquisa em administração: guia para estágios, trabalhos de conclusão, dissertações e estudos de casos. 3. ed. São Paulo: Atlas, 2007.

SAMARA, B. S.; BARROS, J. C. Pesquisa de marketing. Conceitos e metodologia. 3. ed. São Paulo: Pearson Prentice Hall, 2007.

SILVA, H. M. Gestão do conhecimento e inteligência competitiva em organizações: uma abordagem conceitual. Revista de Iniciação Científica da FFC, v. 7, n. 1, p. 84-93, 2007.

SUA FRANQUIA.COM. Franquia da Cacau Show. Disponível em: <https://www. suafranquia.com/franquias/alimentacao/doces-e-salgados/franquia-cacau-show/ suporte.html>. Acesso em: 14 nov. 2015.

TOLEDO, J. C. Gestão da mudança da qualidade do produto. Gestão \& Produção, v. 1, n. 2, p. 104-124, ago. 1994.

VALLANDRO, L. F. J.; TREZ, G. Visão Baseada em Recursos, Estratégia, Estrutura e Performance da Firma: Uma Análise das Lacunas e Oportunidades de Pesquisas Existentes no Campo da Administração Estratégica. In: ENCONTRO DE ESTUDOS EM ESTRATÉGIA, 6., 2013. Anais... Bento Gonçalves, 2013.

\section{Como citar este artigo:}

ABNT

CRUZ, Karla Dayane Bezerra; PEREIRA, Laise Cristina Lima. Vantagem competitiva de uma franquia no segmento de chocolates finos: um estudo na perspectiva Resource-Based View (RBV). RACE, Revista de Administração, Contabilidade e Economia, Joaçaba: Ed. Unoesc, v. 16, n. 3, p. 1035-1058, set./dez. 2017. Disponível em: <http://editora.unoesc.edu.br/index.php/race>. Acesso em: dia/mês/ano. 


\begin{abstract}
APA
Cruz, K. D. B., \& Pereira, L. C. L. (2017). Vantagem competitiva de uma franquia no segmento de chocolates finos: um estudo na perspectiva Resource-Based View (RBV). RACE, Revista de Administração, Contabilidade e Economia, 16(3), 10351058. Recuperado em dia/mês/ano, de http://editora.unoesc.edu.br/index.php/race
\end{abstract}

